EGU2020-10495

https://doi.org/10.5194/egusphere-egu2020-10495

EGU General Assembly 2020

(c) Author(s) 2021. This work is distributed under

the Creative Commons Attribution 4.0 License.

\title{
The Evolution of Subantarctic Fronts, Deep Ocean Ventilation and Flow Vigour at the Agulhas Plateau: Surface-Deep Coupling Across Climate Transitions of the past $3 \mathrm{Ma}$
}

\author{
Aidan Starr ${ }^{1}$, Ian R. Hall ${ }^{1}$, Stephen Barker ${ }^{1}$, Jeroen van der Lubbe ${ }^{1,3}$, Sidney R. Hemming ${ }^{2}$, \\ Francisco J. Jimenez-Espejo ${ }^{4}$, and Nambiyathodi Lathika ${ }^{5}$ \\ ${ }^{1}$ School of Earth and Ocean Sciences, Cardiff University, Cardiff, United Kingdom \\ ${ }^{2}$ Lamont-Doherty Earth Observatory of Columbia University,Palisades, NY, USA \\ ${ }^{3}$ Faculty of Earth and Life Sciences, VU University, Amsterdam, The Netherlands \\ ${ }^{4}$ Instituto Andaluz de Ciencias de la Tierra Consejo Superior de Investigaciones Científicas, Universidad de Granada, Armilla, \\ Granada, Spain \\ ${ }^{5}$ Department of Isotope Geochemistry, National Centre for Polar and Ocean Research, Goa, India
}

The geometry of large-scale deep ocean circulation is closely linked to processes occurring in the Southern Ocean (SO). The SO is the 'window' through which much of the world's ocean interior interacts with the atmosphere, and understanding the complex relationships coupling SO dynamics to deep circulation can provide valuable insights into biogeochemical and physical processes important to global climate. Of particular interest is how these processes interacted with, and behaved under different climate states, such as the glacial-interglacial cycles of the Pleistocene (0-2.8 Ma), and the intensification of Northern Hemisphere glaciation during the transition from the warm Mid-Pliocene (3.3-3.1 Ma) to the early Pleistocene. Here, we utilise new composite sediment core records $\left(41^{\circ} \mathrm{S}, 25^{\circ} \mathrm{E}, 2700-2900 \mathrm{~m}\right.$ water depth) to reconstruct deep chemical and physical ventilation at the Agulhas Plateau, as well as the competing presence of warm Subtropical waters vs cold Subantarctic waters in the surface, over the past $\sim 3 \mathrm{Ma}$. We present records of the 'sortable silt' flow speed proxy, the stable isotope $\left(\delta^{18} \mathrm{O}, \delta^{13} \mathrm{C}\right)$ composition of benthic foraminifera, bulk sediment element concentrations, and the accumulation of ice-rafted debris (IRD). The sortable silt proxy demonstrates that deep physical ventilation is largely decoupled from deep chemical ventilation as indicated by benthic $\delta^{13} \mathrm{C}$, with higher flow speeds coincident with more depleted $\delta^{13} \mathrm{C}$. Furthermore, deep ventilation is related to changes in the terrigenous sediment composition: deep flow speeds and $\delta^{13} \mathrm{C}$ vary concurrently with bulk sediment geochemistry (K/Al, Ti). At the Agulhas Plateau, we interpret deep chemical ventilation and near-bottom flow speeds to reflect changes in the advection of northern-sourced deep waters (e.g. North Atlantic Deep Water and its glacial equivalent) and meridional variability in the location of the deep-reaching Antarctic Circumpolar Current (ACC) and its associated fronts. The presence of IRD at the Agulhas Plateau is controlled primarily by the equatorward survivability far-travelling Antarctic icebergs, and therefore represents the relative presence of cold, iceberg-bearing Subantarctic Zone (SAZ) surface waters. Generally, at times of high near-bottom flow speed and more 'southern' terrigenous sediment composition, IRD is higher, implying a meridional expansion 
of the SAZ. Together, these proxy records provide a continuous and long-term insight into the evolution of coupled surface-deep conditions at the Agulhas Plateau. We postulate that these conditions may reflect the wider geometry of ocean circulation in the SO, documenting the interactions between the ACC and circum-Antarctic fronts with the upwelling, conversion, and export of deep water masses. Our records represent the first multi-proxy reconstruction of this system across climate transitions of the past $\sim 3 \mathrm{Ma}$, allowing us to explore its evolution across a range of timescales, from million-year to orbital-scale. Furthermore, by measuring multiple proxies on the same samples, we are able to determine the relative phasing between different processes independent of chronostratigraphic uncertainties, for example the timing of SAZ changes vs perturbations in deep ocean circulation at the site. 